
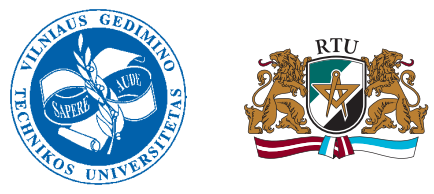

\title{
DYNAMIC RESPONSE OF RIGID PAVEMENT UNDER MOVING TRAFFIC LOAD WITH VARIABLE VELOCITY
}

\author{
Yang Zhong ${ }^{1 \bowtie}$, Yuanyuan $\mathrm{Gao}^{2}$, Mingliang $\mathrm{Li}^{3}$ \\ School of Civil and Hydraulic Engineering, Dalian University of Technology, No.4 Linggong Street, \\ 116024 Dalian, China \\ E-mails: ${ }^{1}$ zhongyang58@163.net; ${ }^{2}$ gaoyuanyuan2286@163.com; ${ }^{3}$ lis.1221@163.com
}

\begin{abstract}
In this paper, the dynamic response of an infinite plate resting on an elastic foundation subjected to moving traffic load with variable velocity (accelerating or decelerating) is investigated by using a triple Fourier integral transform in time and space. The effects of the load varying velocity, acceleration and deceleration, are discussed respectively. The numerical results indicate that the main affecting parameters are initial velocity, acceleration or deceleration. Numerical examples are presented to compare the results of static analysis and those of dynamic analysis with a constant, varying velocity. The results show that the dynamic response of rigid pavement under a moving traffic load with variable velocity is not only different from that caused by static load, but also different from that generated by load with a constant moving speed. Displacement of the plate is reduced with increasing the varying velocity and acceleration. But, stresses of the plate increase with the varying velocity at given acceleration.
\end{abstract}

Keywords: rigid pavement, moving traffic load, variable velocity, dynamic responses, acceleration and decelerating, fourier integral transform.

\section{Introduction}

In the analysis of highway and airport pavements a rigid pavement structure is usually regarded as a plate resting on an elastic foundation, which is often modeled as a Winkler foundation. In general, the loads exerted on the plate are moving traffic load such as wheel loads from moving vehicles or airplanes. Moving loads applied to the plate structure with acceleration or deceleration are induced when a vehicle accelerates or decelerates or a plane takes off or lands. In view of this, the investigation of dynamic response of the plate resting on an elastic foundation subjected to moving traffic loads becomes interesting and important. The research findings are helpful for people to understand the dynamic behaviors of highways and airport pavements. Many research findings have appeared in the literature on the dynamic response of a beam resting on a foundation subjected to moving loads and free vibration of plates. Existing research on response to moving loads focused on plate and beam structures without an elastic foundation. Lin and Trethwey (1990) analyzed elastic beams subjected to dynamic loads induced by arbitrary movement of a spring-mass-damper system. Suzuki (1977) studied dynamic behavior of a finite beam subjected to travelling loads with acceleration. Plates on an elastic foundation subjected to moving loads have only at- tracted the attention of a few researchers. Auersch (2008) investigated the response of layered medium caused by moving loads. Degrande and Schillemans (2001) and Lefeuve-Mesgouez et al. (2000) studied free fields vibration yielded by high-speed moving loads. Hussein and Hunt (2006) investigated tracks dynamic response under oscillating moving loads. Sun (2006) analyzed the dynamic displacement of slab caused by a moving load with constant speed. Huang and Thambiratnam (2002) used the finite strip method to study the dynamic response of plates under moving loads. Vallabhan et al. (1991) used the refined model to study the dynamic behavior of rectangular plates on layered soil medium. Existing research on dynamic analysis of plates on elastic foundations pertains to analytical models with simple and regular boundary conditions. Gbadeyan and Oni (1992) investigated the response to an arbitrary number of concentrated moving masses of a rectangular plate continuously supported by an elastic Pasternak-type foundation using a double Fourier finite integral transformation technique. Kim and Roesset (1998) investigated the dynamic response of a plate of infinite extent on an elastic foundation subjected to moving loads of constant amplitude and harmonic loads using Fourier transforms. However, to the authors' knowledge, dynamic response of rigid pavement under 
moving traffic load with variable velocity (acceleration or deceleration) has not been well studied before. This paper studies the dynamic response of an infinite plate resting on an elastic foundation. The effects of acceleration, initial moving velocity and initial position are investigated and discussed. In order to validate the formulations derived in the paper, the numerical results are presented and compared with results for the same problem with a constant velocity. The dynamic response of a plate resting on an elastic foundation subjected to moving traffic loads is interesting and important. The results can be applied to understand the dynamic behaviors of highway and airport pavements.

\section{Governing equations and solution analysis}

Based on the classical small deflection theory of plate, the governing equation for dynamic lateral deflection $w(x, y, t)$ in an $x-y$ Cartesian coordinate system is

$$
\begin{gathered}
D\left[\frac{\partial^{4} w(x, y, t)}{\partial x^{4}}+\frac{\partial^{4} w(x, y, t)}{\partial x^{2} \partial y^{2}}+\frac{\partial^{4} w(x, y, t)}{\partial y^{4}}\right]+ \\
K w(x, y, t)+C \frac{\partial w(x, y, t)}{\partial t}+\rho h \frac{\partial^{2} w(x, y, t)}{\partial t^{2}}= \\
F(x, y, t),
\end{gathered}
$$

where $D$ - the flexural rigidity of the plate defined by $D=\frac{E h^{3}}{12\left(1-\mu^{2}\right)}, M P a \cdot m^{3} ; \rho-$ density, $\mathrm{MN} / \mathrm{m}^{2} ; h$-thickness, $\mathrm{m}$; $E$ - modulus, MPa; $\mu$ - Poisson's ratio; $C$ - damping coefficient of the plate respectively, $\mathrm{MN} / \mathrm{m}^{3} ; K$ - the reaction modulus of the foundation, $\mathrm{MN} / \mathrm{m}^{3} ; F(x, y, t)$ the external dynamic load acting on the plate surface, $\mathrm{N} ; t$ - denotes time, s.

The plate is assumed to extend to infinity in the horizontal plane. The load pressure within the contact area is assumed to be uniformly distributed in a rectangular area. In this paper, the loads moving along the $x$ direction are considered, which can be represented in the form

$$
\begin{gathered}
F(x, y, t)= \\
F_{0}\{U[x+b-X(t)] U[y+c]-U[x-b-X(t)] U[y-c]\},
\end{gathered}
$$

where $F_{0}$ - the amplitude function of the load, $\mathrm{N} ; U$ - the unit step function; $b$ and $c$ - the half lengths of the rectangle sides of the load distribution, respectively, $\mathrm{m} ; X(t)$ denotes a function describing the motion of the force at time $t$ defined as

$$
X(t)=x_{0}+V t+\frac{1}{2} a t^{2},
$$

where $x_{0}$ - the load position, $\mathrm{m} ; V$ - the initial speed, $\mathrm{m} / \mathrm{s} ; \boldsymbol{a}$ - the constant acceleration, $\mathrm{m} / \mathrm{s}^{2}$. This function describes a uniform decelerating or accelerating motion. The uniform velocity type of motion is given by

$$
X(t)=x_{0}+V t .
$$

Eqs (1)-(3) are total formulations for the analytical model of the plate on elastic foundation, subjected to moving concentrated loads.

In order to solve the problem described above a double dimension Fourier transform is adopted as defined by following:

$$
\bar{f}(\varsigma, \eta, t)=\int_{-\infty}^{\infty} \int_{-\infty}^{\infty} f(x, y, t) e^{-i(\varsigma x+y \eta)} d x d y .
$$

The inverse Fourier transform is

$$
f(x, y, t)=\frac{1}{4 \pi^{2}} \int_{-\infty}^{\infty} \int_{-\infty}^{\infty} f(\varsigma, \eta, t) e^{i(\varsigma x+y \eta)} d \varsigma d \eta
$$

Using the Fourier transform defined as Eq (5), the Eq (1) can be presented as

$$
\begin{gathered}
\frac{d^{2} \bar{w}(\xi, \eta, t)}{d t^{2}}+\frac{C}{\rho h} \frac{d \bar{w}(\xi, \eta, t)}{d t}+ \\
\frac{1}{\rho h}\left[D\left(\xi^{2}+\eta^{2}\right)^{2}+K\right] \bar{w}(\xi, \eta, t)= \\
\frac{\bar{F}(\xi, \eta, t)}{\rho h}
\end{gathered}
$$

Fourier transforming Eq (3) gives

$$
\begin{gathered}
\bar{F}(\xi, \eta, t)= \\
F_{0} \int_{-\infty}^{\infty} \int_{-\infty}^{\infty}\left\{\begin{array}{l}
U[x+b-X(t)] U[y+c]- \\
U[x-b-X(t)] U[y-c]
\end{array}\right\} e^{-i(\varsigma x+\eta y)} d x d y= \\
F_{0} \frac{4 \sin \xi b}{\xi} \frac{\sin \eta c}{\eta} e^{i \xi\left[x_{0}+t\left(V+\frac{1}{2} a t\right)\right]} .
\end{gathered}
$$

Substituting Eq (8) into Eq (7) and using Duhamel Integration and the inverse Fourier transform, the solution

$$
w(x, y, t)=\frac{F_{0}}{\rho h \pi^{2}} \int_{-\infty}^{\infty} \int_{-\infty}^{\infty} \int\left\{\frac{\sin \xi b \sin \eta c}{\xi \eta} e^{i \xi\left[x_{0}+\tau\left(V+\frac{1}{2} a \tau\right)\right]-B(t-\tau)} \times \frac{\sin A(t-\tau)}{A} e^{i(\varsigma x+\eta y)}\right\} d \xi d \eta d \tau,
$$

where $B=\frac{C}{2 \rho h} ; A=\sqrt{D\left(\xi^{2}+\eta^{2}\right)^{2} / \rho h-B^{2}}$. 
Using Mathematica software and integrating for $\tau$ in $\mathrm{Eq}(9)$ gives

$$
\begin{gathered}
w(x, y, t)=\frac{(-1)^{\frac{1}{4} F_{0}}}{\rho h \pi^{2} \sqrt{2 a \pi}} \times \\
\int_{-\infty}^{\infty} \int_{-\infty}^{\infty} \frac{e^{i\left[\xi\left(x+x_{0}\right)+\eta y+\frac{(A+i B-\xi B)^{2}}{2 a \xi}\right]-p t}}{A} \frac{\sin \xi b \sin \eta c}{\xi \eta}\left\{e^{A\left(\frac{2 B}{a \xi}-i t\right)}\left[\operatorname{erf}\left(Z_{1}\right)-\operatorname{erf}\left(Z_{2}\right)\right]+e^{i A\left(\frac{2 V+a t}{a}\right)}\left[\operatorname{erf}\left(Z_{3}\right)-\operatorname{erf}\left(Z_{4}\right)\right]\right\} d \xi d \eta
\end{gathered}
$$

where $\operatorname{erf}(x)=\frac{2}{\sqrt{\pi}} \int_{0}^{x} e^{-t^{2}} d t$ is the error function:

$Z_{1}=\frac{(1+i)[\xi(V+a t)-A+i B]}{2 \sqrt{a \xi}} ; \quad Z_{2}=\frac{(1+i)(\xi V-A+i B)}{2 \sqrt{a \xi}} ; \quad Z_{3}=\frac{(1+i)(\xi V+A+i B)}{2 \sqrt{a \xi}} ; \quad Z_{4}=\frac{(1+i)[\xi(V+a t)+A+i B]}{2 \sqrt{a \xi}}$.

The transverse stresses are the longitudinal stresses at the bottom of the plate that can be obtained respectively from

$$
\begin{array}{r}
\sigma_{x}(x, y, t)=\frac{E h}{\left(1-\mu^{2}\right)}\left(\frac{\partial^{2} w}{\partial x^{2}}+\mu \frac{\partial^{2} w}{\partial y^{2}}\right)=\frac{-(-1)^{\frac{1}{4}} F_{0} E h}{\rho h \pi^{2} \sqrt{2 a \pi}\left(1-\mu^{2}\right)} \times \\
\int_{-\infty}^{\infty} \int_{-\infty}^{\infty}\left(\xi^{2}+\mu \eta^{2}\right) \frac{e^{i\left[\xi\left(x+x_{0}\right)+\eta y+\frac{(A+i B-\xi B)^{2}}{2 a \xi}\right]-p t}}{A} \frac{\sin \xi b \sin \eta c}{\xi \eta}\left\{e^{A\left(\frac{2 B}{a \xi}-i t\right)}\left[\operatorname{erf}\left(Z_{1}\right)-\operatorname{erf}\left(Z_{2}\right)\right]+e^{i A\left(\frac{2 V+a t}{a}\right)}\left[\operatorname{erf}\left(Z_{3}\right)-\operatorname{erf}\left(Z_{4}\right)\right]\right\} d \xi d \eta .
\end{array}
$$

$$
\begin{array}{r}
\sigma_{y}(x, y, t)=\frac{-E h}{\left(1-\mu^{2}\right)}\left(\frac{\partial^{2} w}{\partial y^{2}}+\mu \frac{\partial^{2} w}{\partial x^{2}}\right)=\frac{-(-1)^{\frac{1}{4}} F_{0} E h}{\rho h \pi^{2} \sqrt{2 a \pi}\left(1-\mu^{2}\right)} \times \\
\int_{-\infty}^{\infty} \int_{-\infty}^{\infty}\left(\mu \xi^{2}+\eta^{2}\right) \frac{e^{i \cdot\left[\xi\left(x+x_{0}\right)+\eta y+\frac{(A+i B-\xi B)^{2}}{2 a \xi}\right]-p t}}{A} \frac{\sin \xi b \sin \eta c}{\xi \eta}\left\{e^{A\left(\frac{2 B}{a \xi}-i t\right)}\left[\operatorname{erf}\left(Z_{1}\right)-\operatorname{erf}\left(Z_{2}\right)\right]+e^{i A\left(\frac{2 V+a t}{a}\right)}\left[\operatorname{erf}\left(Z_{3}\right)-\operatorname{erf}\left(Z_{4}\right)\right]\right\} d \xi d \eta .
\end{array}
$$

The stresses considered in this study are tensile stresses in the longitudinal direction at the bottom of the plate because the transverse stresses are smaller than the longitudinal stresses.

\section{Dynamic response to moving accelerated/decelerated load}

An infinite plate on the Winkler foundation subjected to a moving traffic load with variable velocity (accelerating or decelerating) is considered. The concerned data used in all the numerical examples are as follows: $E=3.45 \times 10^{4} \mathrm{MPa}, \mu=$ $0.15, K=1.36 \mathrm{MN} / \mathrm{m}^{3}, C=2.0 \times 10^{5} \mathrm{MN} / \mathrm{m}^{3}, b=0.35 \mathrm{~m}$, $h=0.30 \mathrm{~m}, c=0.25 \mathrm{~m}, F_{0}=1.0 \times 10^{5} \mathrm{~N}, t=1.0 \mathrm{~s}$,

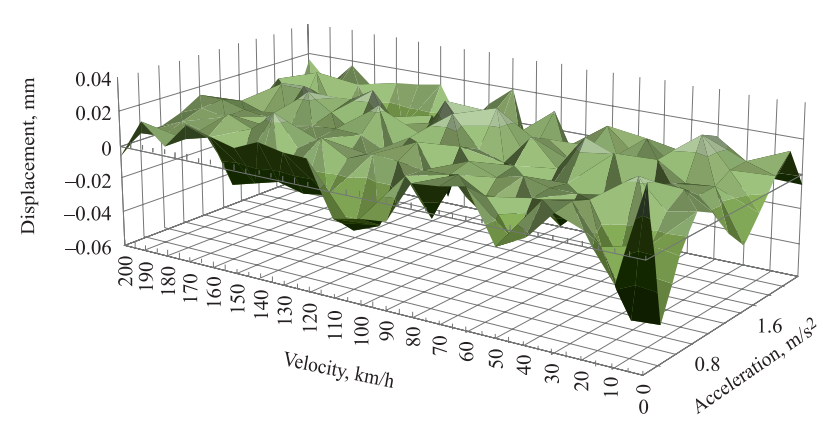

Fig. 1. Max displacements of the plate with different accelerations and velocities 


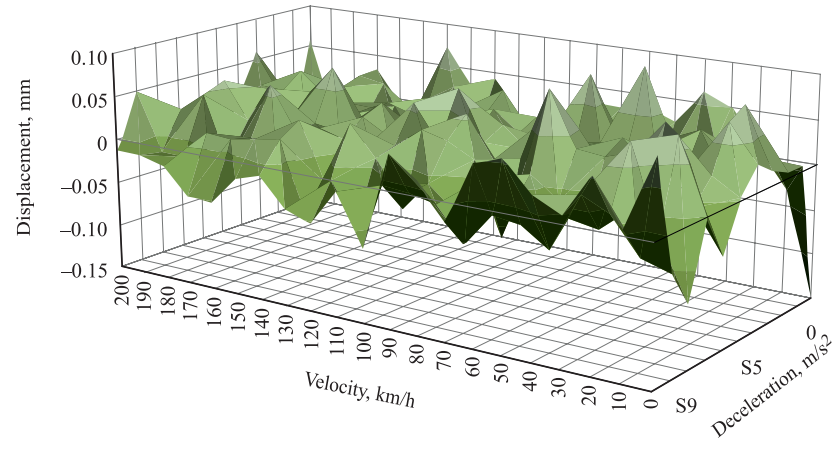

Fig. 2. Max displacements of the plate with different decelerations and velocities

$x_{0}=0.0$. A range of values of acceleration and velocity are examined in these examples from which the effect of acceleration and velocity on the dynamic response of the plate are well investigated.

Figs 1 and 2 show the max deflections of the plate with different acceleration, deceleration and velocity at time of $1 \mathrm{~s}$ and at load position of $0.5 \mathrm{~m}$. Fig. 3 shows stresses of the plate with different acceleration and velocity at time of $1 \mathrm{~s}$ and at load position of $0.5 \mathrm{~m}$. It can be seen that the max deflections and stresses of the plate change with the load varying acceleration, deceleration and velocity and have different max values. This feature can also be seen in Figs 4-9 which illustrate the dynamic deflections and stresses of the plate under the different varying load acceleration, deceleration and velocity when one of them is fixed.

From Fig. 4, it can be seen that when the load acceleration is fixed, the deflection of the plate increases with the load varying velocity and there are peak values. At the acceleration of $0.2 \mathrm{~m} / \mathrm{s}^{2}$ and the velocity of $100 \mathrm{~km} / \mathrm{h}$, the displacement reaches the max value. When the acceleration is given $2 \mathrm{~m} / \mathrm{s}^{2}$ the displacement will have a peak value at the velocity of $130 \mathrm{~km} / \mathrm{h}$.

Fig. 5 shows the results of displacement with different velocities when the deceleration is given. It can be seen that these are similar to the results shown in Fig. 4; the deflection of the plate increases with the load varying velocity and there are peak values. But the increasing speed is larger than that when the load moves with acceleration. Also, at the deceleration of $-0.2 \mathrm{~m} / \mathrm{s}^{2}$ and velocity of $100 \mathrm{~km} / \mathrm{h}$ the displacement has max value. But when deceleration is fixed at $-0.2 \mathrm{~m} / \mathrm{s}^{2}$, the displacement has a peak value at the velocity of $190 \mathrm{~km} / \mathrm{h}$.

Figs 6 and 7 illustrate the results of displacement with different acceleration and deceleration when the load moving velocity is fixed. It can be seen that the displacement reduces with the acceleration and deceleration increasing when the load moving velocity is fixed.

Fig. 8 presents the results of the stresses of the plate with different acceleration when the load varying velocity is fixed. It can be seen that the stresses of the plate reduce with the increasing acceleration and deceleration when the

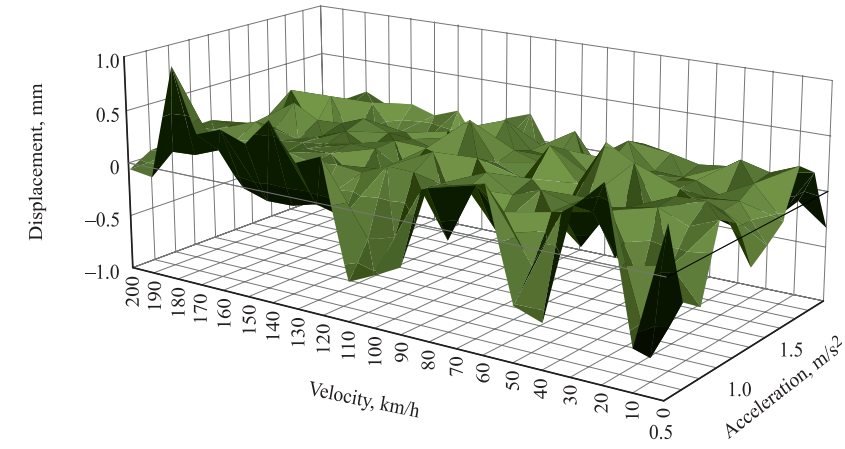

Fig. 3. Max stress of the plate with different accelerations and velocities

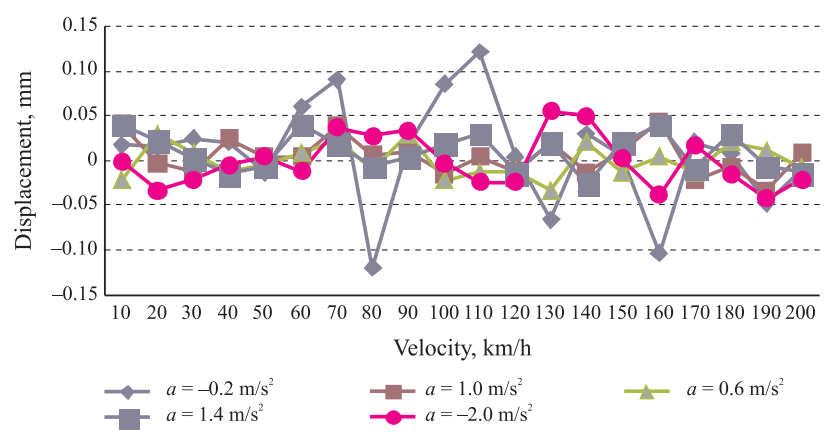

Fig. 4. Max displacement of the plate with different velocities and fixed acceleration

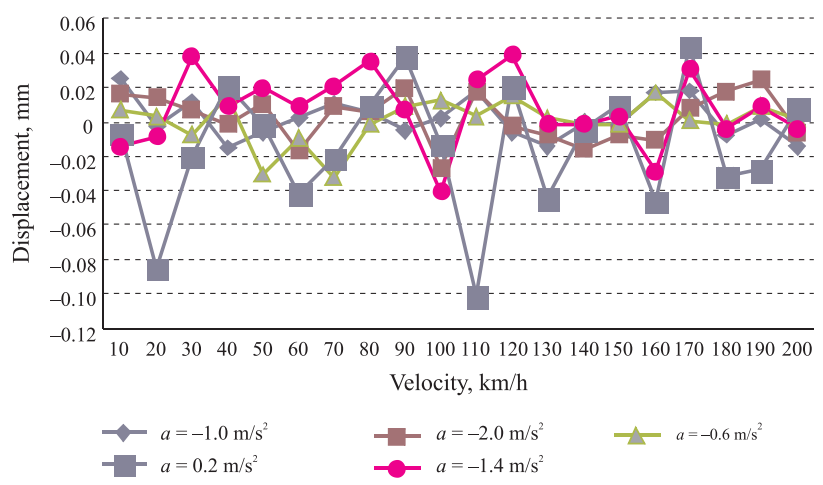

Fig. 5. Max displacement of the plate with different velocities and fixed deceleration

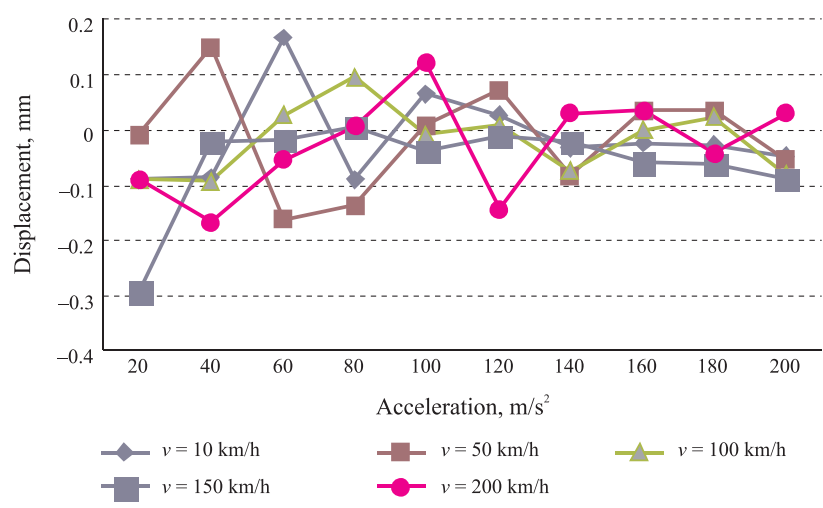

Fig. 6. Max displacement of the plate with different accelerations and fixed velocity 


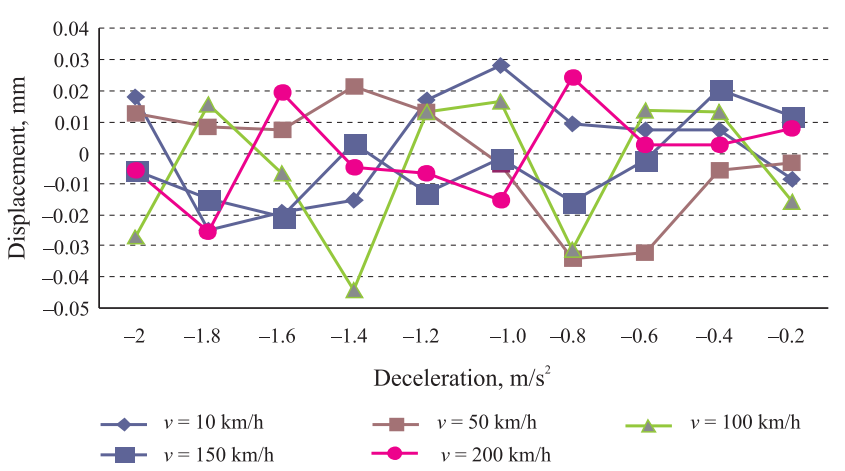

Fig. 7. Max displacement of the plate with different decelerations and fixed velocity

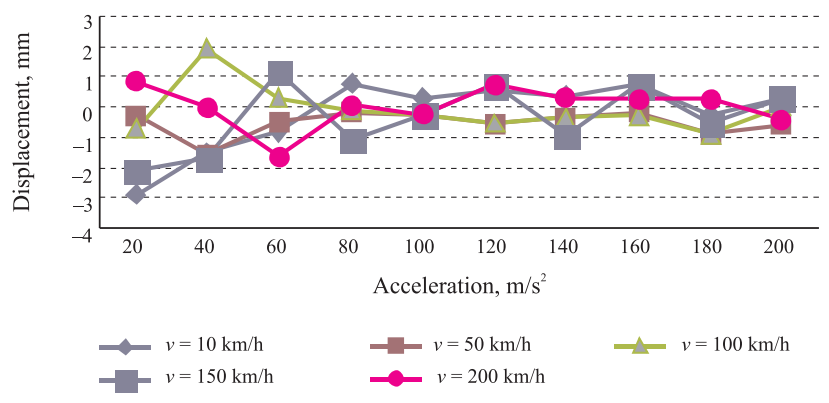

Fig. 8. Max stresses of the plate with different accelerations and fixed velocity

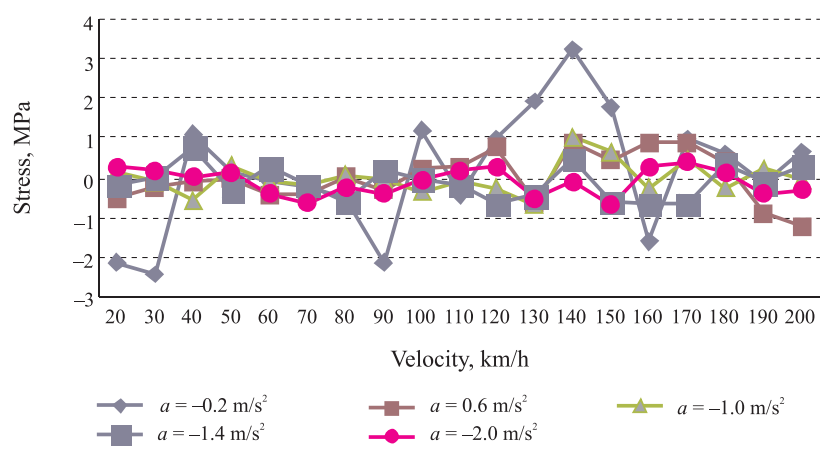

Fig. 9. Max stresses of the plate with different velocities and fixed acceleration

load varying velocity is fixed. At small values of velocity (less than $50 \mathrm{~km} / \mathrm{h}$ ) the reduction is slow. At large values of velocity the reduction is rapid.

Fig. 9 is the results of the stresses of the plate with different velocity when the load varying acceleration is fixed. It can be seen that the stresses of the plate increase with the acceleration increasing when the load varying velocity is fixed. At the acceleration of $0.2 \mathrm{~m} / \mathrm{s}^{2}$ and the velocity of $140 \mathrm{~km} / \mathrm{h}$ the stresses reach the max value. When the acceleration is given $2 \mathrm{~m} / \mathrm{s}^{2}$ the plate stresses reach peak values at the velocity of $170 \mathrm{~km} / \mathrm{h}$.

\section{Conclusions}

In this paper, the dynamic response of an infinite plate on an elastic foundation subjected to a moving traffic load with variable velocity (accelerating or decelerating) is investigated via a triple Fourier transform. The effects of the load varying velocity, acceleration and deceleration are also discussed. The numerical results show that the max deflections and stresses of the plate change with the load varying acceleration, deceleration and velocity. Both the deflections and the stresses reach different max values. The dynamic displacements and stresses increase with the load varying velocity and decrease with the load varying acceleration and deceleration. These phenomena suggest that the design of rigid pavements should carefully consider the effect of the dynamic load caused by variable moving vehicles.

\section{References}

Auersch, L. 2008. The Effect of Critically Moving Loads on the Vibrations of Soft Soils and Isolated Railway Tracks, Journal of Sound and Vibration 310(3): 587-607. http://dx.doi. org/10.1016/j.jsv.2007.10.013

Degrande, G.; Schillemans, L. 2001. Free Field Vibrations during the Passage of a Thalys High-Speed Train at Variable Speed, Journal of Sound and Vibration 247(1): 131-144. http:// dx.doi.org/10.1006/jsvi.2001.3718

Gbadeyan, J. A.; Oni, S. T. 1992. Dynamic Response to Moving Concentrated Masses of Elastic Plates on a Non-Winkler Elastic-Foundation, Journal of Sound and Vibration 154(2): 343-358. http://dx.doi.org/10.1016/0022-460X(91)90585-8

Huang, M. H.; Thambiratnam, D. P. 2002. Dynamic Response of Plates on Elastic Foundation to Moving Loads, Journal of Engineering Mechanics-ASCE 128(9): 1016-1022. http://dx.doi. org/10.1061/(ASCE)0733-9399(2002)128:9(1016)

Hussein, M. F. M.; Hunt, H. E. M. 2006. Modelling of Floatingslab Tracks with Continuous Slabs under Oscillating Moving Loads, Journal of Sound and Vibration 297(1-2) 37-54. http:// dx.doi.org/10.1016/j.jsv.2006.03.026

Kim, S. M.; Roesset, J. M. 1998. Moving Loads on a Plate on Elastic Foundation, Journal of Engineering Mechanics 124(9): 1010-1017. http://dx.doi.org/10.1061/(ASCE)07339399(1998)124:9(1010)

Lefeuve-Mesgouez, G.; Le Houédec, D.; Peplow, A. T. 2000. Ground Vibration in the Vicinity of a High-Speed Moving Harmonic Strip Load, Journal of Sound and Vibration 231(5): 1289-1309. http://dx.doi.org/10.1006/jsvi.1999.2731

Lin, Y. H.; Trethewey, M. W. 1990W. Finite Element Analysis of Elastic Beams Subjected to Moving Dynamic Loads, Journal of Sound and Vibration 136(2): 323-342. http://dx.doi. org/10.1016/0022-460X(90)90860-3

Sun, L. 2006. Analytical Dynamic Displacement Response of Rigid Pavements to Moving Concentrated and Line Loads, International Journal of Solids and Structures 43(14-15): 4370-4383. http://dx.doi.org/10.1016/j.ijsolstr.2005.06.105

Suzuki, S. I. 1977. Dynamic Behavior of a Finite Beam Subjected to Travelling Loads with Acceleration, Journal of Sound and Vibration 55(1): 65-70. http://dx.doi.org/10.1016/0022460X(77)90583-1

Vallabhan, C. V. G.; Straughan, W. T.; Das, Y. C. 1991. Refined Model for Analysis of Plates on Elastic Foundations, Journal of Engineering Mechanics 117(12): 2830-2844. http://dx.doi. org/10.1061/(ASCE)0733-9399(1991)117:12(2830)

Received 19 May 2010; accepted 24 February 2011 